\title{
Trade-offs between nutrient circularity and
}

\section{3 environmental impacts in the management of}

\section{organic waste}

5

6

7

Selene Cobo*, Antonio Dominguez-Ramos and Angel Irabien

8 
25 Measuring the circularity of resources is essential to assess the performance of a circular 26 economy. This work aims at proposing an indicator that quantifies how effective a system is at extending the lifetime of its waste components after they have been discarded. The developed indicator was applied to study the circularity of nutrients within a system that handles the organic waste (OW) generated in the Spanish region of Cantabria. A superstructure was developed to determine the optimal configuration of the system. It comprises alternative Unit Processes (UPs) for i) the management of OW, and ii) the application of the recovered products as soil amendment to grow corn. A multi-objective Mixed Integer Linear Programming problem was formulated under two policy scenarios with different source separation rates (SSRs). The problem was optimized according to six objective functions: the circularity indicators of carbon, nitrogen and phosphorus, which are maximized, and their associated environmental impacts to be minimized (global warming, marine eutrophication and freshwater eutrophication). The model was fed with the Life Cycle Assessment results obtained with EASETECH (Environmental Assessment System for Environmental TECHnologies) and the nutrient flows in the agriculture subsystem, which were calculated with DNDC (DeNitrification-DeComposition). It was concluded that improving nutrient circularity paradoxically leads to eutrophication impacts, and increasing the SSR of OW has a positive effect on the carbon footprint of the system.

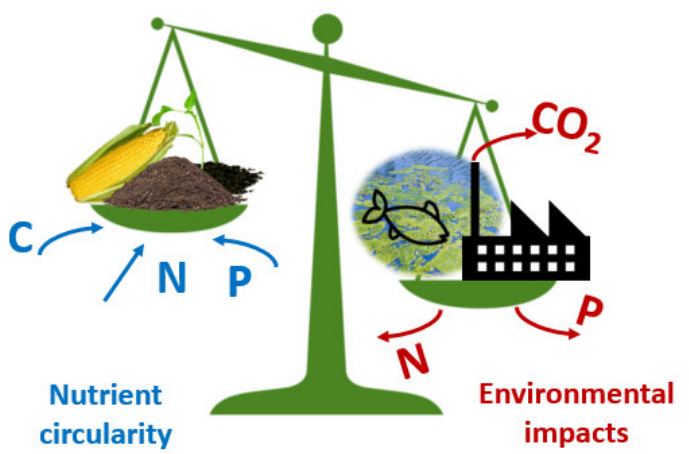




\section{INTRODUCTION}

In the context of a boom of initiatives promoting a circular economy within the European Union, ${ }^{1-3}$ it is the responsibility of researchers to provide policy-makers with the data and tools needed to make informed decisions. Measuring the circularity of resources is key to assessing the performance of a circular economy.

\section{Literature overview}

Several approaches have been presented to tackle this challenge. One study defined a global circularity indicator as the share of material inputs into the global economy that are cycled, subsequently estimating that the global economy was $9.1 \%$ circular in $2015 .{ }^{4}$ Although this indicator provides insight into the global materials metabolism, policy implications cannot be directly derived from it. Instead, an indicator that can be applied to systems design and operation is of more interest to the policy makers.

Some authors suggest that circularity indicators should capture how the differences between the physico-chemical properties of the recovered waste components and the primary resources they displace affect their substitution ratio. ${ }^{4-7}$ Accordingly, Moriguchi ${ }^{5}$ pointed out that the reduction in the requirement for primary resources could be a good indicator of circularity. However, this does not necessarily entail that more waste components are being recovered; it could be the consequence of an increase in the eco-efficiency of the system.

Haupt et al. ${ }^{6}$ suggested that open-loop and closed-loop recycling rates that reflect the efficiency of the recycling processes and the type of application of the recycled components in their next life cycle stage should be used as performance indicators for a circular economy. 
The duration of material retention within a system has also been recommended as an indicator of circularity. ${ }^{7}$ Following this line of thinking, the Ellen MacArthur Foundation proposed the lifetime of a product as one of the parameters used to calculate its circularity indicator. ${ }^{8}$ Although this indicator is useful for companies, it does not provide information about the circularity of the components of the product, since it does not consider their entire life cycle.

The described indicators do not correlate with the quality of the recovered components and they do not reveal how much of the recovered components are consumed again; i.e., to what extent the loop is closed.

The methodology proposed by Cobo et al., ${ }^{9}$ which enables to track waste components within a Circular Integrated Waste Management System (CIWMS), might help overcome these limitations, since CIWMSs encompass not only waste management, but also the processing and consumption of the components recovered from waste and the external raw materials that eventually become waste.

\section{Case study}

This framework is applied to the study of the management of organic waste (OW) in the region of Cantabria, in the north of Spain. The OW generated in Cantabria $\left(83.5 \cdot 10^{3}\right.$ metric ton in 2014) is collected with other discarded household inorganic materials. The OW that is sorted out at the regional mechanical-biological treatment facility is subjected to a windrow composting process. Nonetheless, Directive $2008 / 98 / \mathrm{EC}^{10}$ does not allow the land application of the biostabilized material derived from the composting of the OW separated from the mixed waste stream (mix-OW); only the OW that has been source separated (SS-OW) can be recycled. The expiration of the regional authorization that permitted the sale of the bio-stabilized material as compost until $2018^{11}$ makes it impossible for the current waste management system to comply 
with the legal restraints. The need to retrofit the system represents an opportunity to implement new circularity practices. The interest of recycling $\mathrm{OW}$ lies in the nutrients it contains.

\section{Implications of nutrient recovery}

This study focuses on three essential nutrients to soil amendment: carbon (C), nitrogen (N) and phosphorus (P). Enhancing the circularity of these nutrients within a CIWMS a priori seems to be a strategy that will contribute to closing their natural biogeochemical cycles by avoiding the accumulation of nutrients in one of the Earth's subsystems (atmosphere, hydrosphere, biosphere or lithosphere) at a rate faster than the ecosystems can sustain. Thus, the relevance that a circular economy of nutrients might have to global sustainability challenges should not be underestimated. On the one hand, the forthcoming peak P production, due to the depletion of the global rock phosphate reserves, threatens future food security; ${ }^{12}$ on the other, the anthropogenic interference with the $\mathrm{C}$ and $\mathrm{N}$ biogeochemical cycles to meet the energy and food demands has already caused the transgression of the estimated climate change and $\mathrm{N}$ cycle planetary boundaries within which humanity is expected to operate safely. ${ }^{13}$

Since the nutrient cycles interact with each other, ${ }^{14}$ promoting the circularity of one nutrient might have consequences on the biogeochemical cycles of the others. For instance, increasing Soil Organic Carbon (SOC) stocks may exacerbate $\mathrm{N}_{2} \mathrm{O}$ emissions, ${ }^{15}$ and an increased availability of reactive $\mathrm{N}$ may lead to $\mathrm{C}$ sequestration because of biomass growth. ${ }^{16}$ Another counter-effect related to the land application of the products recovered from $\mathrm{OW}$ is the accumulation of surplus $\mathrm{P}$ in agricultural soils, because the $\mathrm{N}: \mathrm{P}$ ratio in organic fertilizers is lower than the N:P ratio required by crops. ${ }^{17-19}$ 
124 The circularity of $\mathrm{C}, \mathrm{N}$ and $\mathrm{P}$ within a CIWMS and the main impacts associated with the emissions of these elements to the environment (global warming, marine eutrophication and freshwater eutrophication) must be jointly analyzed. Although the recovery of nutrients is a subject that is drawing the attention of the scientific community, ${ }^{20-24}$ the trade-offs between these indicators have not been systematically explored in the literature yet. Therefore, the objectives of this paper are the following:

- To propose a circularity indicator that can be applied to any non-renewable resource and accounts for the extended service of the components recovered from waste.

- To optimize the OW management system in the region of Cantabria, setting as objective functions the maximization of the circularity indicators of $C, N$ and $P$, and the minimization of the global warming, marine eutrophication and freshwater eutrophication impacts.

\section{METHODOLOGY}

Material Flow Analysis (MFA), Life Cycle Assessment (LCA) and multi-objective optimization were applied to determine the optimal configuration of the Cantabrian CIWMS aiming at nutrient recovery from OW. A superstructure comprising the combinations of unit processes a discontinuous line. 


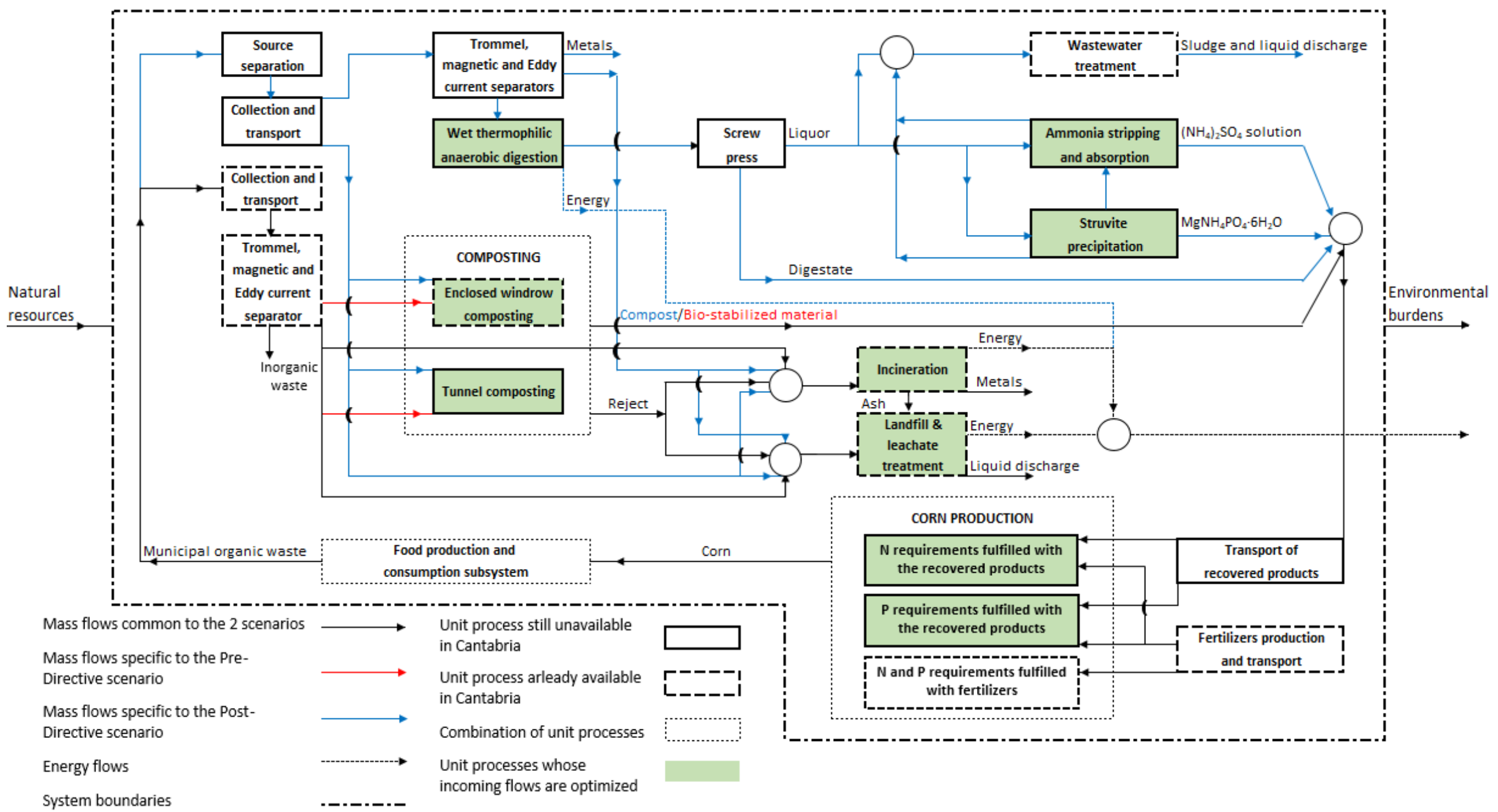

Figure 1. Studied CIWMS 
148 The products recovered from OW were assumed to be applied to land to grow corn, the main

149 fodder crop grown in Cantabria. ${ }^{25}$ The superstructure comprises a set $j$ of UPs for the management of OW and a set $k$ of corn production UPs. The UPs that can handle the solid OW are wet thermophilic anaerobic digestion, windrow composting inside an enclosed building, composting inside a tunnel reactor, incineration and landfill. The ammonia stripping and absorption and the struvite precipitation UPs recover nutrients from the liquid digestate (LD) produced in the anaerobic digestion, which only processes SS-OW after it has been pretreated. ${ }^{26-}$ handle the rejects generated by the other UPs. It is assumed that all the waste processing units are in the same facility. A detailed description of these UPs can be found in Cobo et al. ${ }^{31}$

The nutrient uptake efficiencies of corn (shown in Appendix D of the Supporting Information) differ for each type of applied product (bio-stabilized material, compost, digestate, struvite and ammonium sulphate). As shown in Appendix C of the Supporting Information, $\mathrm{P}$ is in excess with respect to the amount of $\mathrm{N}$ required by corn in all the recovered products except for ammonium sulphate. Consequently, the nutrient flows were modeled so that the optimal approach to corn production can be either based on one of these strategies or on a combination of them:

S1) Application of the amount of recovered product needed to cover the corn $\mathrm{N}$ requirements.

S2) Application of the amount of recovered product needed to cover the corn P requirements.

S3) Application of industrial $\mathrm{N}$ and $\mathrm{P}$ fertilizers $\left(\mathrm{NH}_{4} \mathrm{NO}_{3}\right.$ and $\left.(\mathrm{NH} 4)_{2} \mathrm{HPO}_{4}\right)$. 
172 The alternative combinations of the corn production UPs that can arise from the application of

173 these strategies are shown in Figure 2. The $\mathrm{N}$ and $\mathrm{P}$ requirements of corn are defined as the

174 amounts of these nutrients that yield the maximum average annual crop production that can be

175 achieved in a 100-year timeframe with industrial $\mathrm{N}$ and $\mathrm{P}$ fertilizers. Assuming an $80 \%$ collection

176 rate of the produced corn grain, it corresponds to a net production of 7.11 tons of corn grain per

177 ha per year.

178

179

180

181

182

183

184

185

186

187

188

189

190

191

192

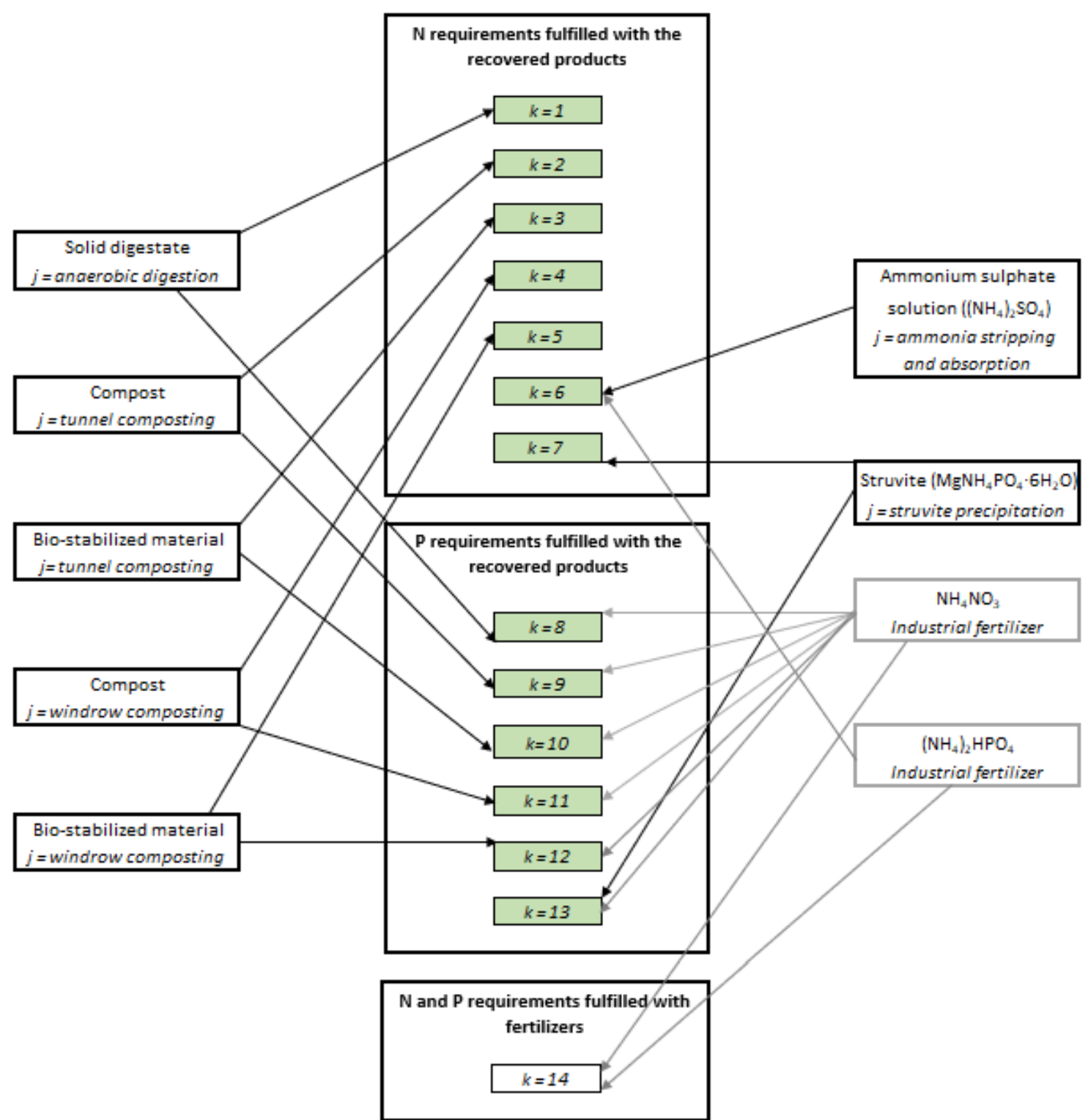

Figure 2. Possible combinations of inputs to the corn production subsystem 
200 A modular LCA approach, where the LCA of the individual UPs of the system is carried out, ${ }^{32,33}$ 201 was performed. The UPs concerning the management of solid OW were modeled with EASETECH $2022.3 .6,^{34}$ which provided their environmental impacts. The nitrate and phosphate leachate, the emissions of $\mathrm{CO}_{2}, \mathrm{~N}_{2} \mathrm{O}$ and $\mathrm{NO}$, the amount of Dissolved Organic Carbon (DOC) consumed by soil microorganisms, the flows of $\mathrm{N}$ and $\mathrm{P}$ uptaken by corn and the amount of nutrients stored in soil per hectare of cultivated corn were calculated with DNDC $9.5 .^{35}$ These results were transferred to EASETECH 2.3.6, where the environmental impacts associated with the land application of the recovered products and corn production were calculated.

208

The results obtained with DNDC and EASETECH were exported as parameters to GAMS (General Algebraic Modeling System) 24.8.1, where the problem was formulated. Figure 3 clarifies the data flows derived from the application of this methodology.

213 The data required to characterize the UPs that integrate the system are compiled in the Supporting Information: waste composition (Appendix A), waste management UPs (Appendix B) and corn production subsystem (Appendix C). 

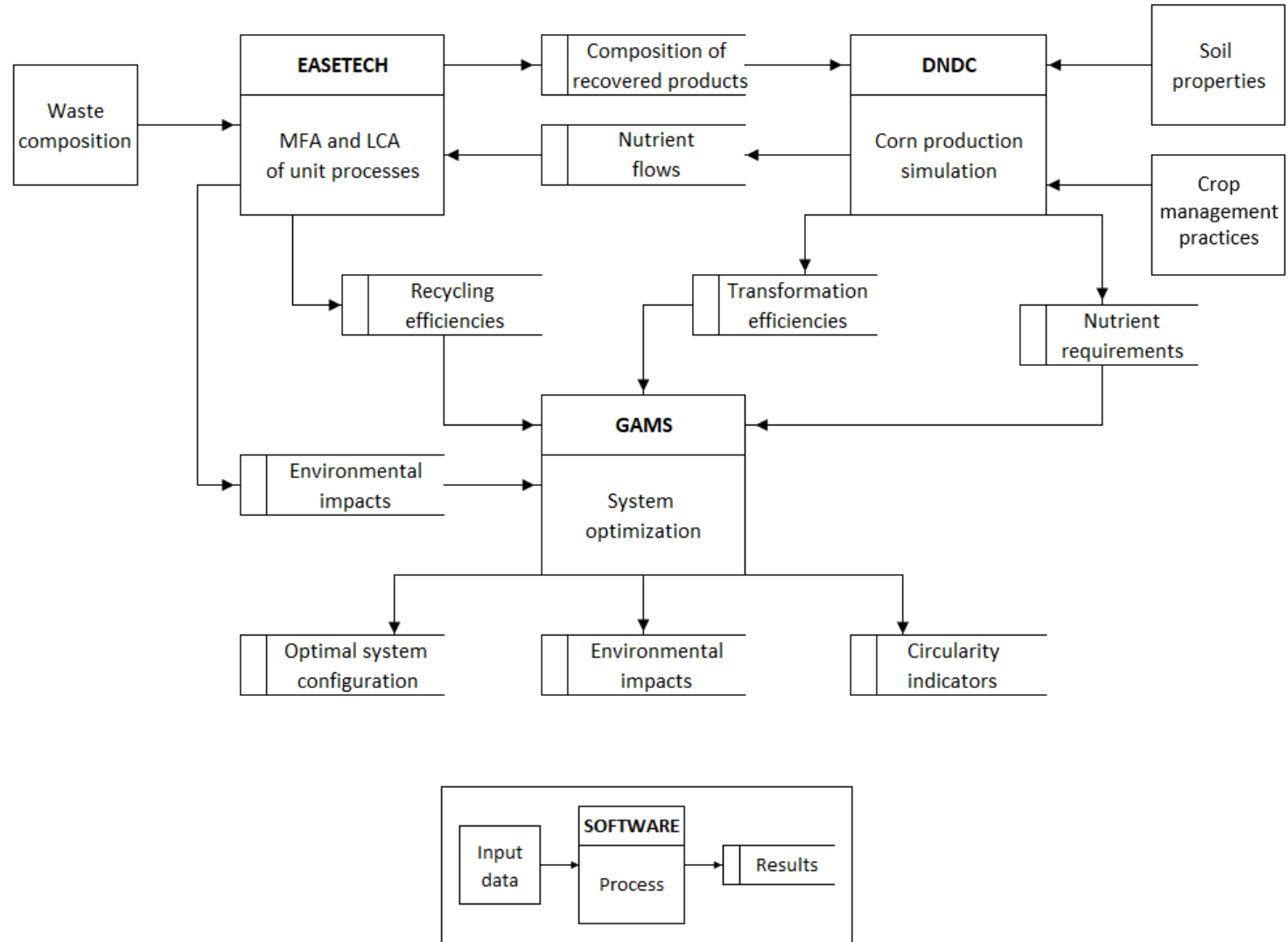

Figure 3. Data flow diagram

\section{DEFINITION OF THE CIRCULARITY INDICATORS}

224 Figure 4 illustrates the flows of the component $i$ of a given waste stream within a CIWMS. The circularity indicator of component $i\left(C I_{i}\right)$ is defined as the amount of component $i$ that extends its lifetime by providing a service in the upstream processes with respect to the amount of that component present in the collected waste. Equation 1 shows how the $C I_{i}$ is calculated for a set of $n$ recycling and preparation for reuse processes and $m$ production processes that valorize this component.

$$
C I_{i}=\frac{\sum_{k=1}^{m} \sum_{j=1}^{n} R_{i j k} \cdot \eta_{r_{i j}} \cdot \eta_{p_{i k}}}{W_{i}}
$$

230 The variables needed for the calculation of $C I_{i}$ are these: 
- $\quad W_{i}$. Amount of component $i$ present in the waste stream (kg).

- $\quad R_{i j k}$. Amount of component $i$ that enters the recycling or preparation for reuse process component $i$ recovered per $\mathrm{kg}$ of component $i$ that enters process $j$ ). recovered component $i$ into a product that will deliver a service in the consumption

$k)$.

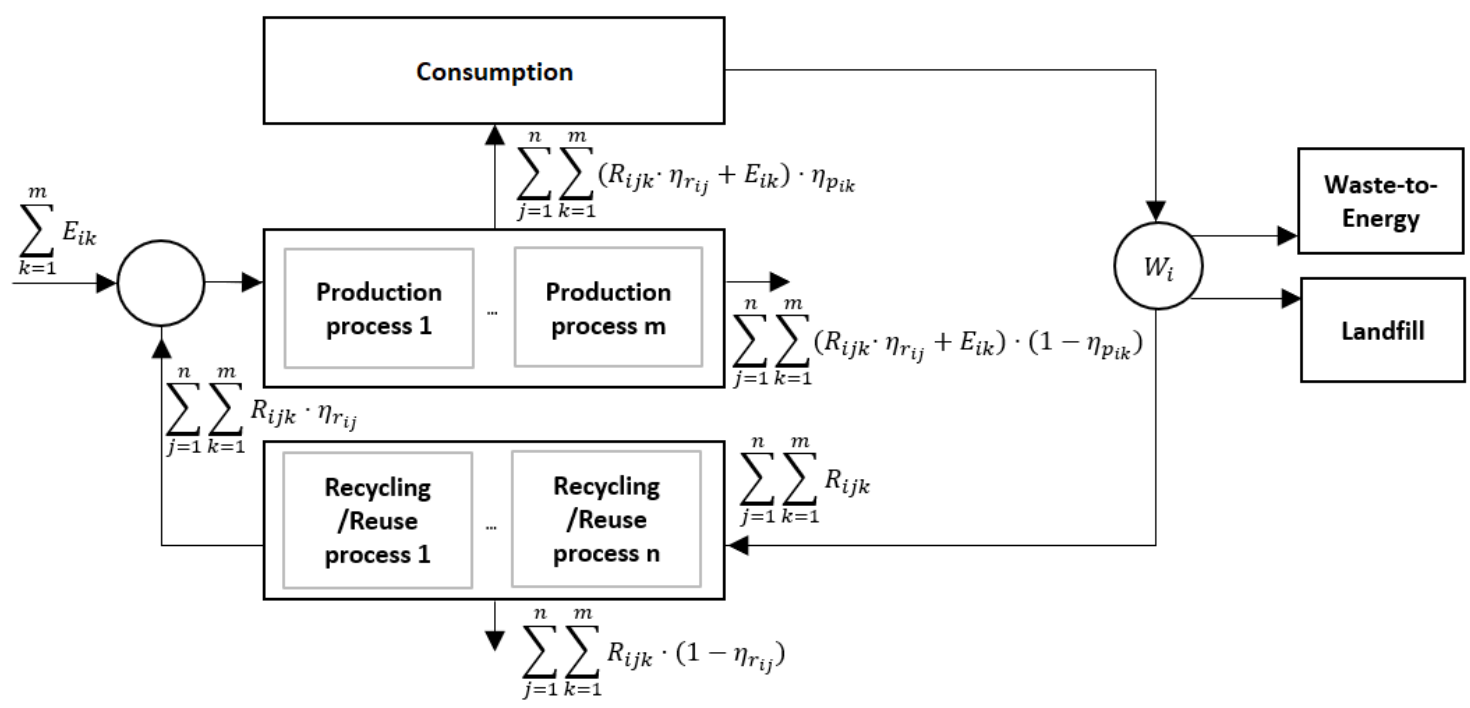

Figure 4. Simplified CIWMS

$C I_{i}$ is dimensionless, its value can range between 0 and 1 . A value of 1 implies that the total amount of component $i$ that was discarded is recovered and reprocessed to enter the consumption subsystem, indicating that there are not any losses of component $i$ in the recycling, preparation for reuse and upstream processes. If $C I_{i}=0$, component $i$ is not recovered at all, but incinerated or landfilled instead. 

quantifying how much of the recovered component is consumed. This indicator does not account per se for the degradation of the waste components after successive cycles, but if the selected time horizon of the study is wide enough, a dynamic analysis should show how for a sustained service demand, the external supply of component $i\left(\sum_{k=1}^{m} E_{i k}\right)$ must increase due to the degradation of the recovered component.

\section{Nutrient circularity indicators}

The circularity indicators of $\mathrm{N}$ and $\mathrm{P}\left(C I_{N}\right.$ and $\left.C I_{P}\right)$ were defined as the amount of nutrient $i$ that is recycled, applied to land and uptaken by corn with respect to the amount of nutrient $i$ present in the collected OW.

262

The same definition cannot be applied to the $\mathrm{C}$ circularity indicator $\left(C I_{C}\right)$, since the $\mathrm{C}$ captured by vegetation in the photosynthesis process does not come from the soil but from the atmosphere.

Besides improving the water-holding capacity of soil and its ability to retain cations in a plant available form, contributing to $\mathrm{C}$ sequestration and promoting the formation of soil structure, ${ }^{36,37}$ the purpose of applying a source of $C$ to land is to feed the soil microorganisms. When these microorganisms decompose the $\mathrm{SOC}$, the decomposed $\mathrm{C}$ is partially lost as $\mathrm{CO}_{2}$, and $\mathrm{DOC}$ is produced as an intermediate that can be consumed by the soil microorganisms. ${ }^{38}$ These microbes are also responsible for the $\mathrm{N}$ fixation, ammonification and nitrification processes that release $\mathrm{N}$ compounds that plants can assimilate; they are essential for crop production. 
Consequently, a different definition was proposed for $C I_{C}$. It was defined as the ratio between the mass of DOC that is recycled, applied to land and consumed by microbes with respect to the amount of $\mathrm{C}$ present in the collected waste.

The values of $\eta_{r_{i j}}$ and $\eta_{p_{i k}}$ required for the calculation of the circularity indicators are compiled in Appendix D of the Supporting Information.

\section{PROBLEM FORMULATION}

A single-period Mixed Integer Linear Programming problem was formulated for the optimization of the decision variables; i.e., the incoming material flows (waste and recovered products) to the green shaded UPs in Figure 1. The problem was optimized according to these objective functions, where $x$ and $y$ represent the continuous and binary variables respectively: the circularity indicators of the studied nutrients, which must be maximized $\left(C I_{C}(x, y), C I_{N}(x, y)\right.$, and $C I_{P}(x, y)$ ), and the selected environmental impacts of the system to be minimized (global warming $G W(x, y)$, marine eutrophication $\operatorname{MEU}(x, y)$ and freshwater eutrophication $F W E(x, y))$

After verifying the trade-offs between the objective functions, a multi-objective problem was formulated as follows:

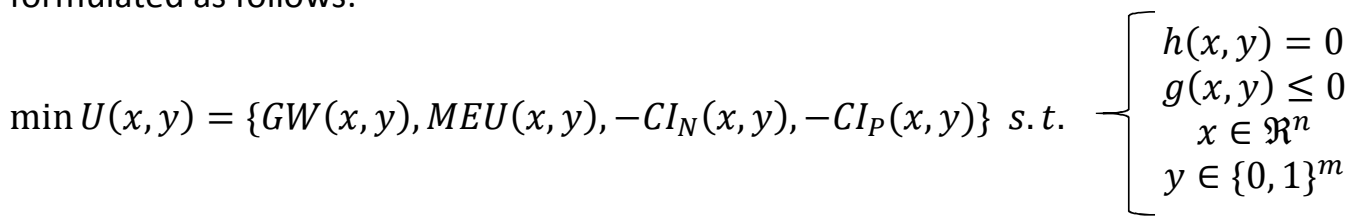

The equations that describe the behavior of the system $(h(x, y)=0)$ are based on the mass balances of the UPs. The problem is subjected to these restrictions $(g(x, y) \leq 0)$ : 
- The area fertilized with the recovered products cannot exceed the available area to grow corn in Cantabria (4810 ha). ${ }^{39}$

- The amount of biodegradable waste sent to landfill must be lower than $35 \%$ of the domestic waste generated in 1995 (170,168 ton) ${ }_{1}^{11}$ as established by Directive 1999/31/EC. ${ }^{40}$

- Windrow and tunnel composting cannot accept waste streams with the same composition.

- SS-OW and mix-OW cannot be mixed in any composting processes.

306

307 The GAMS model comprises a total of 844 equations, 19 inequations, 817 continuous variables and 28 discrete variables. The main input parameters to the models are the source separation rate (SSR), the total area available for corn production and the amount of OW generated yearly in Cantabria.

Different waste collection systems for SS-OW and commingled waste were modeled. It was considered that the composition of SS-OW is $98 \%$ OW and $2 \%$ impurities, which is consistent with documented source separation experiences. ${ }^{41}$ Two scenarios (neglecting and considering the current legislative framework) were analyzed:

- Pre-Directive scenario. Mix-OW can be recycled. The SSR is $0 \%$ and no recycling target is set.

317 The red arrows in Figure 1 represent the flows of mix-OW that can only be composted in $318 \quad$ this scenario.

- Post-Directive scenario. Mix-OW cannot be recycled. To comply with the 50\% OW recycling target established by the Cantabrian waste management plan ${ }^{11}$ for 2020 , a $50 \%$ SSR is set, and an additional restriction is added to the model to ensure that $50 \%$ of the collected OW is composted or anaerobically digested. The blue arrows in Figure 1 represent the flows of SS-OW that are specific to this scenario. 
The multi-objective optimization problem was solved with the CPLEX solver and the $\varepsilon$-constraint method. ${ }^{42}$

\section{MODELING APPROACH AND ASSUMPTIONS}

The boundary that separates the studied CIWMS from the ecosphere (which provides the natural resources consumed by the system and a sink for the generated environmental burdens) and the rest of the technosphere is depicted in Figure 1.

Although crops are managed by farmers under controlled conditions in the technosphere, they produce natural biotic resources. Hence, the boundary between technosphere and ecosphere is difficult to identify for agricultural soils. ${ }^{43}$ One of the strategies recommended by Notarnicola et al. ${ }^{44}$ to overcome the limitations of considering agricultural soils as part of the technosphere, is to include the impacts of crop production on soil. In this study the land application of the recovered products and the production of corn were modeled as a UP. Although the system was optimized for 1 year of operation, the selected 100-year time horizon enabled to account for the loss of soil quality due to soil nutrient depletion caused by the production of consecutive annual crops. The average annual corn production and emission rates in that timeframe were considered.

Corn enters the food production and consumption subsystem, which comprises the upstream processes that transform corn and the other food commodities consumed in Cantabria into OW. It composes the background subsystem of the CIWMS because its configuration does not affect the results of the study ${ }^{45}$ only the flows and the composition of its inputs and outputs (corn and waste) that connect it to other UPs are calculated. 
352 According to Cobo et al., ${ }^{9}$ the primary function of CIWMSs is to recover waste components so

353 that their service life in the upstream processes can be extended. In this case study the elements recovered from OW are used for land fertilization and soil conditioning. Since the studied CIWMS encompasses the entire corn production of the region, the functional unit selected to perform the LCA of the system is defined as the area available to grow corn in Cantabria (4810 ha). ${ }^{39}$

An attributional LCA approach was applied. The electricity generated at incineration, anaerobic digestion and landfill is considered the secondary system function. The direct substitution method was applied by expanding the system boundaries to include the generation of electricity from the Spanish grid mix. A 100\% substitution ratio was assumed.

The characterization factors of each emission were calculated with the hierarchical 100-year perspective of the ReCiPe 1.11 method. The assumptions made by the DNDC model about the distribution of nutrients in the environment can be found in Li et al. ${ }^{46}$ Following the rationale explained by Cobo et al., ${ }^{9,31}$ only the biogenic $C$ present in animal and vegetable food waste (which can i) leach into the water, ii) be emitted to the atmosphere, or iii) be stored either in the landfill or the soil as a result of the land application of the recovered products, as shown in Appendix $\mathrm{C}$ of the Supporting Information) was considered neutral. The $\mathrm{CO}_{2}$ derived from the decomposition of SOC was also quantified as fossil C.

Regarding the limitations of the model, the environmental impacts related to capital goods were excluded from the analysis. Moreover, this work assumes that all the $\mathrm{P}$ is in mineral form and accessible for plants. Studies have shown that most of the P in the products recovered from OW is in mineral form, but not all of it. ${ }^{47-50}$ 
377 On the contrary, the mineralization of organic $\mathrm{N}$ is quantified by the DNDC biogeochemical

378 model. The organic/inorganic $\mathrm{N}$ ratio was assumed to be $93 / 7$ for the compost and bio-stabilized material, ${ }^{50}$ and $62.96 / 37.04$ for the solid digestate. ${ }^{51}$

380

381 The DNDC model assumes a 60\% microbial efficiency to calculate the amount of $C$ incorporated into microbial biomass in amended soils, defined as the ratio of $\mathrm{C}$ assimilated into microbial biomass to residue $\mathrm{C}$ released by decomposition. ${ }^{46}$

RESULTS AND DISCUSSION

The results of the problem optimization determine the system configuration; i.e., the UPs that the system comprises and their incoming flows of waste and recovered products. The values of the objective functions and the decision variables that optimize each objective function for the two studied scenarios are compiled in Figure 5. Figure 5A shows the optimal flows of OW and LD handled by the $j$ UPs. The optimal flows of the recovered products into the $k$ corn production UPs (Figure 5B) are shown along with the area fertilized with the recovered products. The contribution of the UPs to the environmental impacts of the optimal system configurations of each scenario are depicted in Figure 6. 


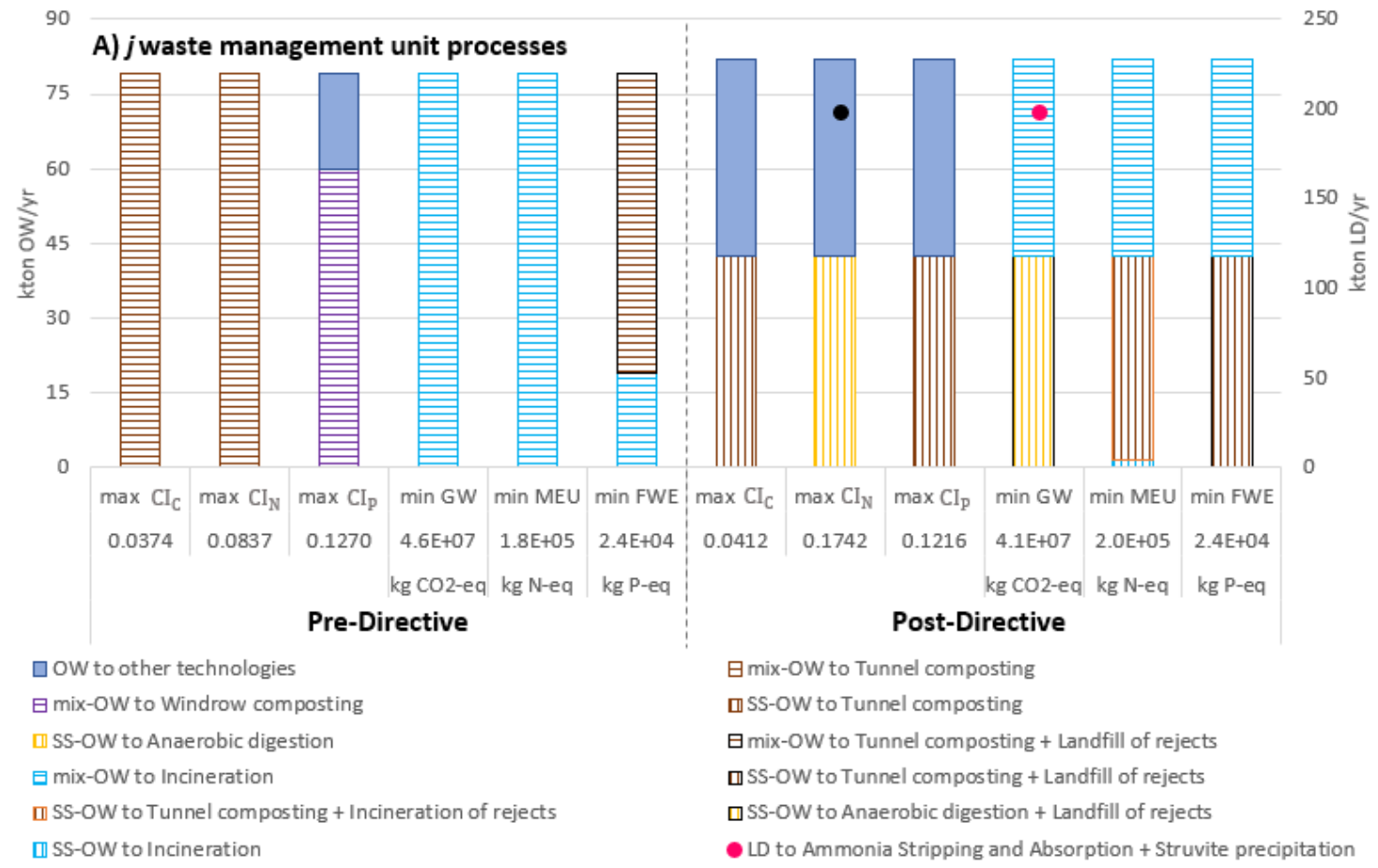

- LD to Ammonia stripping and absorption

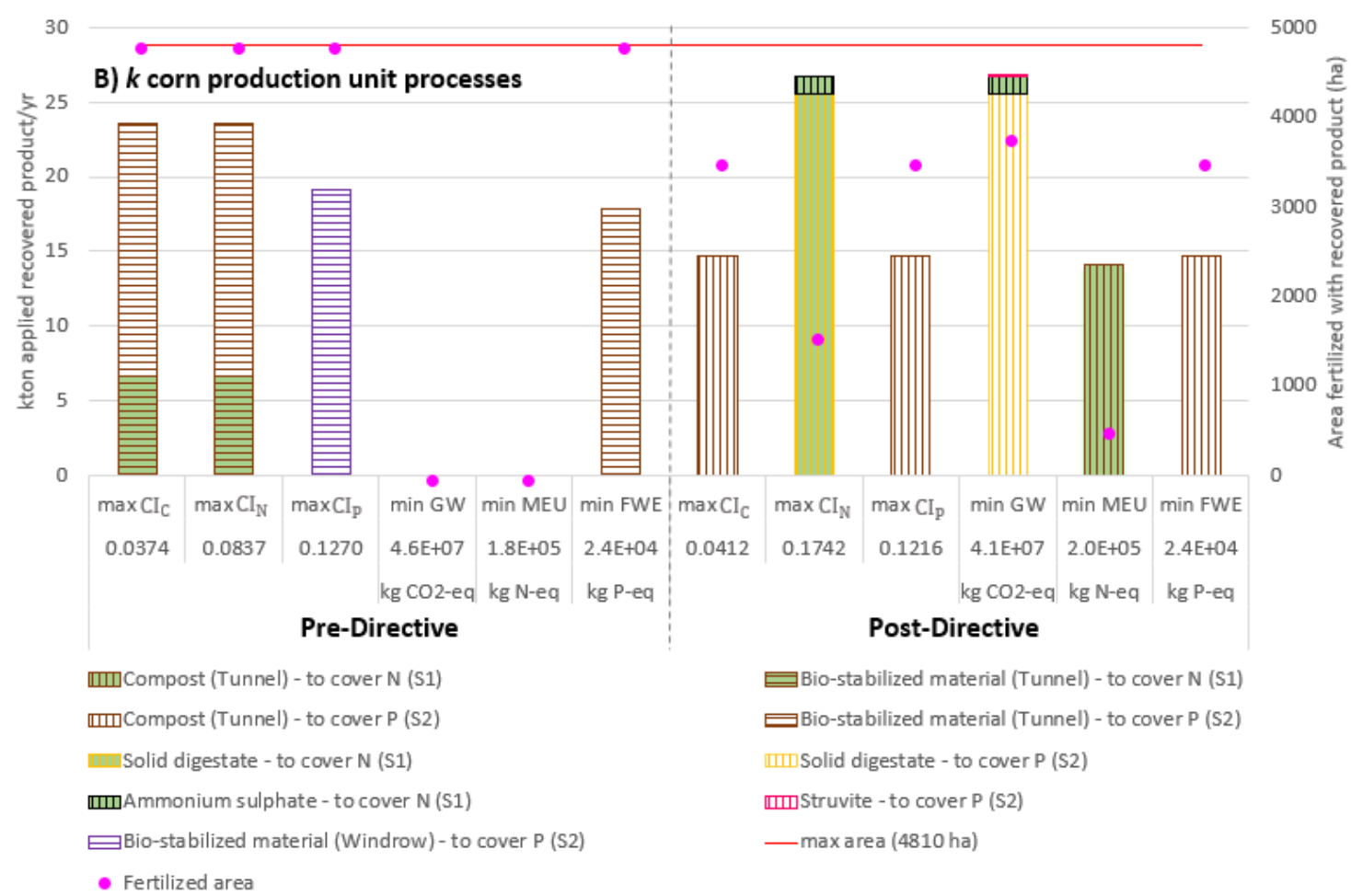

Figure 5. Values of the objective functions and decision variables for the optimization of the

Pre-Directive and Post-Directive scenarios

The flows of OW shown in Figure 5A are lower in the Pre-Directive scenario because part of the separation required for the pretreatment of mixed waste. 
404 There are several system configurations that lead to the maximization of a given circularity

405 indicator, because the UPs that manage the rejects do not affect the corn production subsystem, and thus they do not contribute to closing the nutrient loops. By analogy, in the Post-Directive scenario where mix-OW cannot be recycled, the selection of any UP for its management will result in the same circularity indicators. This is the reason the maximization of the circularity indicators in Figure 5A only shows the UPs that contribute to recirculate nutrients.

The amount of $\mathrm{P}$ present in the mix-OW collected in the Pre-Directive scenario is more than enough to cover the $\mathrm{P}$ requirements of the corn produced in Cantabria under the hypothesis of this work. However, the $\mathrm{N}$ present in OW cannot fertilize all the land available for corn production in any of the studied scenarios. Consequently, strategies S1 and S2 must be combined in the Pre-Directive scenario to maximize $C I_{C}$ and $C I_{N}$. As Figure 5B shows, more area is fertilized with the recovered products in the Pre-Directive scenario because of the higher amount of OW that can be recycled, which makes farmers less dependent on industrial fertilizers (strategy S3). Oppositely, the optimization of all the objective functions are partially based on strategy S3 in the Post-Directive scenario.

420

The optimization of some objective functions provides duplicate or very similar results (freshwater eutrophication and $C I_{P}$ on the one hand, $C I_{C}$ and different circularity indicators in each scenario on the other). To avoid redundant results, freshwater eutrophication and $C I_{C}$ were not considered in the next part of the study, focused on a multi-objective optimization of the other four objective functions. 


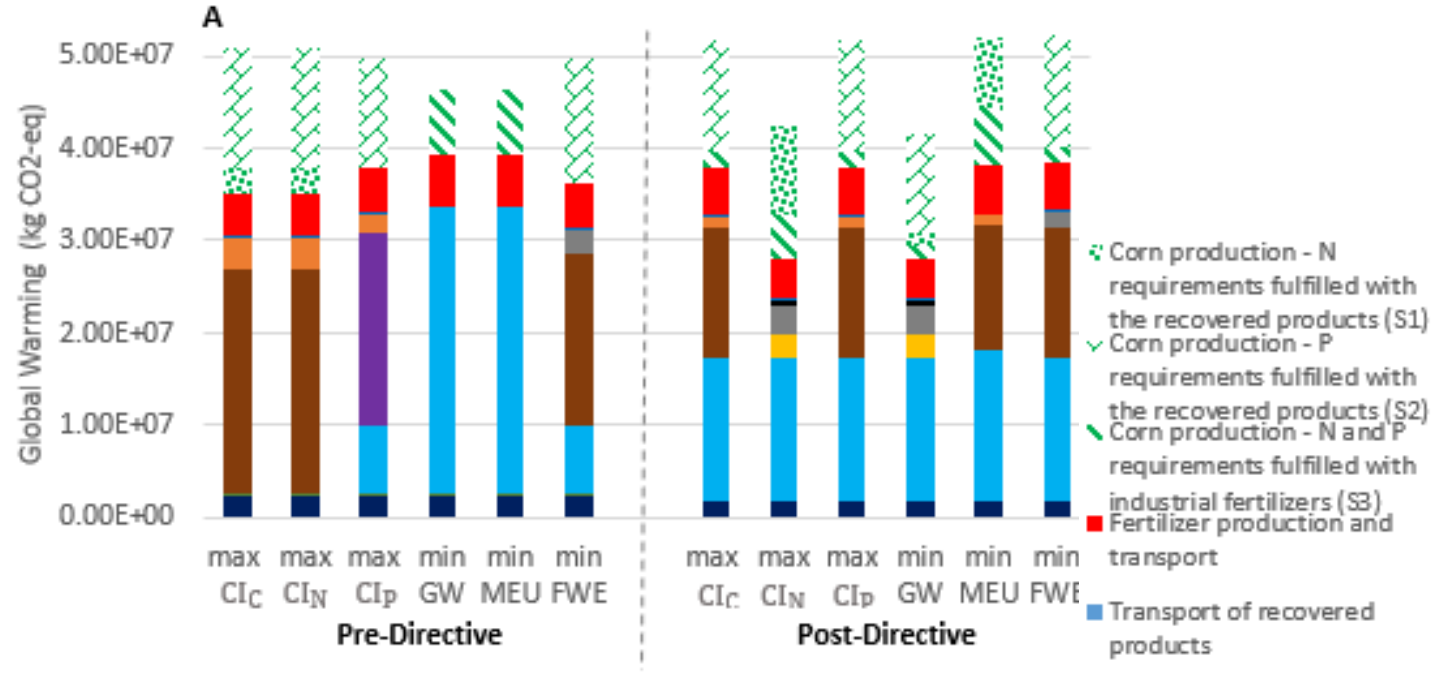

438

439

$3.00 \mathrm{E}+05$

- Liquid digesta te treatment -

440

441

442

443

444

445

446

447

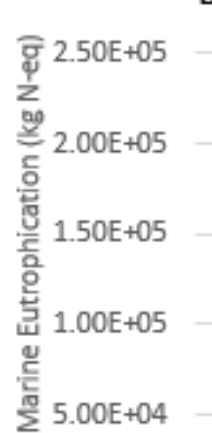

448

449

450

451

452

453

454

455

456

457

458

459

460

Figure 6. Contribution of the UPs to the environmental impacts in the Pre-Directive and Post- 
464 Figure 7 shows the Pareto fronts of the two scenarios, where each point is better than the others

465 in at least one of the values of the objective functions. Global warming and marine eutrophication are normalized with respect to the maximum value of the two scenarios.

467

As the results of the DNDC simulations show, if industrial fertilizers, ammonium sulphate or struvite (inorganic fertilizers) are exclusively applied to soil, the corn Nitrogen Use Efficiency (NUE, defined as the fraction of $\mathrm{N}$ input harvested as product $)^{52}$ decays over time because of the depletion of SOC. The opposite occurs when bio-stabilized material, compost and digestate (organic fertilizers) are applied, due to their $\mathrm{C}$ rich composition. However, the mean NUE obtained for the 100-year time horizon if inorganic fertilizers are applied to land is higher than the NUE achieved after the soil application of the organic fertilzers, because the share of plant available inorganic $\mathrm{N}$ in the latter is low. This implies that more $\mathrm{N}$ leaches when the organic fertilizers with a high organic $\mathrm{N}$ content are applied to land. These results are supported by previous studies that highlight that the $\mathrm{N}$ leaching rate of organic fertilzers is higher than that of inorganic fertilizers..$^{53,54}$

As Figures $6 \mathrm{~B}$ and $6 \mathrm{C}$ indicate, the corn production subsystem is the main contributor to the eutrophication impacts. In both scenarios the marine eutrophication impacts increase with the $C I_{N}$, being the values of these two objective functions higher in the Post-Directive scenario. A similar correlation cannot be established between $C I_{P}$ and freshwater eutrophication because, unlike $\mathrm{N}$, which tends to leach as nitrate when it is applied to soil, $\mathrm{P}$ is strongly sorbed onto soil particles; in fact its major environmental losses can be attributed to erosion. ${ }^{55}$

The Pre-Directive scenario, where the minimum amount of OW that must be recycled is not restricted, relies on incineration and the application of industrial fertilizers. Figure $6 \mathrm{~A}$ shows 
that, although the production of industrial fertilizers is very energy intensive, ${ }^{56}$ the carbon

490 footprint associated with their land application is lower than that of the organic fertilizers, a fraction of which degrades to $\mathrm{CO}_{2}$ after their land application. Thus, as Figure $7 \mathrm{~A}$ shows, in the Pre-Directive scenario as $C I_{N}$ increases, the $\mathrm{CO}_{2}$-eq emissions increase too.

Anaerobic digestion is the UP that handles OW with the lowest carbon footprint. Hence, the minimum carbon footprint achieved at the Post-Directive scenario, the only one where SS-OW can be subjected to anaerobic digestion, is lower than in the Pre-Directive scenario. Moreover, since the $\mathrm{N}$ recycling efficiency of anaerobic digestion and the LD UPs is higher than that of the other UPs, the land application of the products derived from anaerobic digestion also maximizes $C I_{N}$. Therefore, as shown in Figure 7B, in the Post-Directive scenario as the $C I_{N}$ increases, the carbon footprint of the system decreases.

Regarding $C I_{P}$, it shows a similar trend to the $C I_{N}$ in the Pre-Directive scenario, whereas no clear trend can be appreciated in the Post-Directive scenario, where the maximimization of $C I_{P}$ is based on the application of compost to cover the soil $\mathrm{P}$ requirements, and the maximization of $C I_{N}$ on the application of ammonium sulphate and solid digestate to fulfill the soil $\mathrm{N}$ needs, which leads to the accumulation of $\mathrm{P}$ in soil. The values of $C I_{P}$ are lower in the Post-Directive scenario because of the restriction that prevents mix-OW from being recycled.

508

A sensitivity analysis was performed to ascertain the consequences that a $20 \%$ decrease in the values of two key parameters have on the results. The Spanish legislation prioritizes electricity

511 from the biogas produced at landfills and anaerobic digestion facilities over other sources of 512 non-renewable electricity. Notwithstanding, the electricity generated from waste incineration 513 does not have priority access to the grid. ${ }^{57}$ The sensitivity analysis considered that $80 \%$ of the 514 electricity generated from the incineration of OW replaced the electricity from the Spanish grid 
515 mix. On the other hand, it is hard to estimate the composition of SS-OW, since pilot experiments

516 for the source separation of OW have not been carried out in Cantabria. The sensitivity analysis

517 assumed that the fraction of OW in the SS-OW was $78.4 \%$.

The results of the single-objective optimization of each scenario under the conditions of the uncertainty analysis are compiled in Appendix E of the Supporting Information. The main difference in the values of the decision variables after the performance of the sensitivity analysis is that the freshwater eutrophication impacts of incineration exceed those of landfill. Thus, landfill is selected over incineration when the freshwater eutrophication impacts are minimized. As expected, the results of the sensitivity analysis led to slightly higher environmental impacts in both scenarios and lower circularity indicators in the Post-Directive scenario.

Figure 7 proves that the environmental impacts associated with increasing the circularity of nutrients cannot be overlooked. Whereas in the pre-Directive scenario there is a clear opposite trend between the environmental impacts and the circularity of nutrients, the behavior of the system in the Post-Directive scenario, subject to more restrictions and with more available UPs, is more complex.

The findings of this study suggest that increasing the SSR of OW leads to a reduction in the carbon footprint of the system. Although the results indicate that increasing the circularity of $\mathrm{N}$ has detrimental eutrophication impacts, these are highly dependent on the sensitivity of the receiving environment; ${ }^{58}$ thus general conclusions cannot be drawn.

Before selecting a system configuration that meets the sustainability concerns and satisfies the interests of all the stakeholders involved in waste management and the purchase of the recovered products, a trade-off between the studied indicators must be identified. Moreover, 
541 additional impact categories that quantify the environmental impacts associated with the

542 presence of heavy metals or organic pollutants in the recovered products, such as human

543 toxicity or ecotoxicity, should be included in the analysis. However, the feasibility of any system

544 configuration cannot be demonstrated until an economic analysis is performed.

545

546 

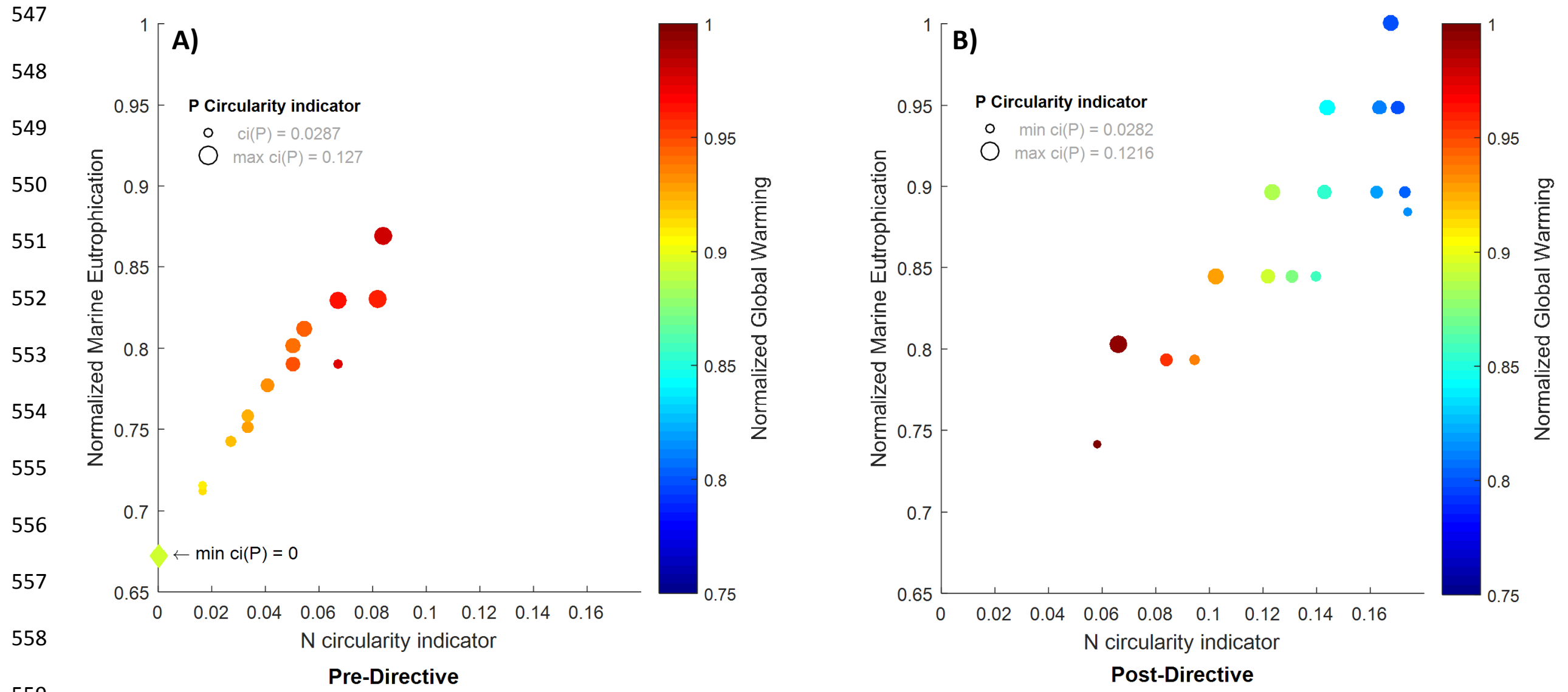

560

Figure 7. Pareto points for the Pre-Directive and Post-Directive scenarios 
562

563 C-Carbon

$564 \mathrm{Cl}_{\mathrm{C}}-$ Carbon circularity indicator

$565 \mathrm{Cl}_{N}-$ Nitrogen circularity indicator

$566 \mathrm{Cl}_{\mathrm{p}}-$ Phosphorus circularity indicator

567 CIWMS - Circular Integrated Waste Management System

568 DOC - Dissolved Organic Carbon

569 LCA - Life Cycle Assessment

570 LD - Liquid digestate

571 MFA - Material Flow Analysis

572 mix-OW - Organic waste separated from the mixed waste stream

$573 \quad N-$ Nitrogen

574 NUE - Nitrogen Use Efficiency

575 OW - Organic waste

$576 \quad$ P-Phosphorus

577 SOC - Soil Organic Carbon

578 SSR - Source Separation Rate

579 SS-OW - Source separated organic waste

580 UP - Unit Process

581

582

\section{SUPPORTING INFORMATION}

584

585 Waste composition, model data, sensitivity analysis. 
The authors acknowledge the financial support from the Spanish MECD (FPU15/01771) and MINECO (CTQ2016-76231-C2-1R).

592

593

1. Closing the loop - An EU action plan for the Circular Economy. European Commission: Brussels, 2015; http://eur-lex.europa.eu/resource.html?uri=cellar:8a8ef5e8-99a011e5-b3b7-01aa75ed71a1.0012.02/DOC_1\&format=PDF.

2. Domenech, T.; Bahn-Walkowiak, B. Transition Towards a Resource Efficient Circular 601 Sci. Technol. 2015, 49, 12206-12213.

4. The circularity gap report. An analysis of the circular state of the global economy. Circle economy: Amsterdam, 2018; https://www.circularity-gap.world/report.

5. Moriguchi, Y. Material flow indicators to measure progress toward a sound materialcycle society. J. Mater. Cycles Waste Manage. 2007, 9, 112-120.

6. Haupt, M.; Vadenbo, C.; Hellweg, S. Do We Have the Right Performance Indicators for the Circular Economy?: Insight into the Swiss Waste Management System. J. Ind. Ecol. 2017, 21, 615-627. 
7. Franklin-Johnson, E.; Figge, F.; Canning, L. Resource duration as a managerial indicator for Circular Economy performance. J. Clean. Prod. 2016, 133, 589-598.

8. Circularity Indicators. An approach to measuring circularity. Methodology; Ellen MacArthur Foundation, 2015; https://www.ellenmacarthurfoundation.org/programmes/insight/circularity-indicators

9. Cobo, S.; Dominguez-Ramos, A.; Irabien, A. From linear to circular integrated waste management systems: A review of methodological approaches. Resour. Conserv. Recycl. 2017, DOI 10.1016/j.resconrec.2017.08.003.

10. Directive on waste and repealing certain Directives. Directive 2008/98/EC, 2008; http://eur-lex.europa.eu/legal-content/En/TXT/?uri=celex\%3A32008L0098.

11. Plan de residuos de la Comunidad Autónoma de Cantabria 2016 - 2022; Gobierno de Cantabria, Consejería de Universidades e Investigación, Medio Ambiente y Política Social: Santander, 2016; http://www.medioambientecantabria.es/documentos_contenidos/64293_2.versionini cialPR.pdf.

12. Cordell, D.; Drangert, J.-L.; White, S. The story of phosphorus: Global food security and food for thought. Global Environ. Change 2009, 19, 292-305.

13. Rockström, J.; Steffen, W.; Noone, K.; Persson, A.; Chapin III, F. S.; Lambin, E.; Lenton, T. M.; Scheffer, M.; Folke, C.; Schellnhuber, H. J.; Nykvist, B.; de Wit, C. A.; Hughes, T.; van der Leeuw, S.; Rodhe, H.; Sörlin, S.; Snyder, P. K.; Costanza, R.; Svedin, U.; Falkenmark, M.; Karlberg, L.; Corell, R. W.; Fabry, V. J.; Hansen, J.; Walker, B.; Liverman, D.; Richardson, K.; Crutzen, P.; Foley, J. Planetary boundaries: Exploring the safe operating space for humanity. Ecol. Soc. 2009, 14(2):32.

14. Likens, G.E.; Bormann, F.H.; Johnson, N.M. Interactions between major biogeochemical cycles in terrestrial ecosystems. In Some perspectives of the major biogeochemical cycles; Likens, G.E., Ed.; John Wiley \& Sons: Chichester, 1981; pp 93-109. 
15. Lal, R. Soil carbon sequestration impacts on global climate change and food security. Science 2004, 304, 1623-1627.

16. Kroeze, C.; Hofstra, N.; Ivens, W.; Löhr, A.; Strokal, M.; van Wijnen, J. The links between global carbon, water and nutrient cycles in an urbanizing world - the case of coastal eutrophication. Curr. Opin. Environ. Sustainability 2013, 5, 566-572.

17. Hanserud, O. S.; Cherubini, F.; Øgaard, A. F.; Müller, D. B.; Brattebø, H. Choice of mineral fertilizer substitution principle strongly influences LCA environmental benefits of nutrient cycling in the agri-food system. Sci. Total Environ. 2018, 615, 219-227.

18. Schoumans, O.F. Phosphorus leaching from soils: process description, risk assessment and mitigation. Ph.D. Dissertation, Wageningen University, Wageningen, The Netherlands, 2015.

19. Rowe, H.; Withers, P. J. A.; Baas, P.; Chan, N. I.; Doody, D.; Holiman, J.; Jacobs, B.; Li, H.; MacDonald, G. K.; McDowell, R.; Sharpley, A. N.; Shen, J.; Taheri, W.; Wallenstein, M.; Weintraub, M. N. Integrating legacy soil phosphorus into sustainable nutrient management strategies for future food, bioenergy and water security. Nutr. Cycl. Agroecosyst. 2016, 104, 393-412.

20. Yao, Y.; Martinez-Hernandez, E.; Yang, A. Modelling nutrient flows in a simplified local food-energy-water system. Resour. Conserv. Recycl. 2018, DOI 10.1016/j.resconrec.2018.02.022.

21. Tonini, D.; Martinez-Sanchez, V.; Astrup, T. F. Material resources, energy, and nutrient recovery from waste: Are waste refineries the solution for the future? Environ. Sci. Technol. 2013, 47, 8962-8969.

22. Wang, X.; Guo, M.; Koppelaar, R. H. E. M.; Van Dam, K. H.; Triantafyllidis, C. P.; Shah, N. A Nexus Approach for Sustainable Urban Energy-Water-Waste Systems Planning and Operation. Environ. Sci. Technol. 2018, 52, 3257-3266. 
23. Knoop, C.; Tietze, M.; Dornack, C.; Raab, T. Fate of nutrients and heavy metals during two-stage digestion and aerobic post-treatment of municipal organic waste. Bioresour. Technol. 2018, 251, 238-248.

24. Yoshida, H.; ten Hoeve, M.; Christensen, T. H.; Bruun, S.; Jensen, L. S.; Scheutz, C. Life cycle assessment of sewage sludge management options including long-term impacts after land application. J. Clean. Prod. 2018, 174, 538-547.

25. Los pastos en Cantabria y su aprovechamiento. Memoria; Centro de Investigación y Formación Agrarias:

Santander, 2006; http://cifacantabria.org/Documentos/memoria.pdf.

26. Ariunbaatar, J.; Panico, A.; Esposito, G.; Pirozzi, F.; Lens, P. N. L. Pretreatment methods to enhance anaerobic digestion of organic solid waste. Appl. Energy 2014, 123, 143-156.

27. Bernstad, A.; la Cour Jansen, J. Separate collection of household food waste for anaerobic degradation - Comparison of different techniques from a systems perspective. Waste Manage. 2012, 32, 806-815.

28. Bernstad, A.; Malmquist, L.; Truedsson, C.; la Cour Jansen, J. Need for improvements in physical pretreatment of source-separated household food waste. Waste Manage. 2013, 33, 746-754.

29. Carlsson, M.; Holmström, D.; Bohn, I.; Bisaillon, M.; Morgan-Sagastume, F.; Lagerkvist, A. Impact of physical pre-treatment of source-sorted organic fraction of municipal solid waste on greenhouse-gas emissions and the economy in a Swedish anaerobic digestion system. Waste Manage. 2015, 38, 117-125.

30. Carlsson, M.; Naroznova, I.; Moller, J.; Scheutz, C.; Lagerkvist, A. Importance of food waste pre-treatment efficiency for global warming potential in life cycle assessment of anaerobic digestion systems. Resour. Conserv. Recycl. 2015, 102, 58-66. 
31. Cobo, S.; Dominguez-Ramos, A.; Irabien, A. Minimization of Resource Consumption and Carbon Footprint of a Circular Organic Waste Valorization System. ACS Sustainable Chem. Eng. 2018, 6, 3493-3501.

32. Steubing, B.; Mutel, C.; Suter, F.; Hellweg, S. Streamlining scenario analysis and optimization of key choices in value chains using a modular LCA approach. Int. J. Life Cycle Assess. 2016, 21, 510-522.

33. Haupt, M.; Kägi, T.; Hellweg, S. (2018). Modular life cycle assessment of municipal solid waste management. Waste Manage. 2018, DOI:10.1016/j.wasman.2018.03.035.

34. Clavreul, J.; Baumeister, H.; Christensen, T. H.; Damgaard, A. An environmental assessment system for environmental technologies. Environ. Model. Softw. 2014, 60, $18-30$.

35. Gilhespy, S. L.; Anthony, S.; Cardenas, L.; Chadwick, D.; del Prado, A.; Li, C.; Misselbrook, T.; Rees, R. M.; Salas, W.; Sanz-Cobena, A.; Smith, P.; Tilston, E. L.; Topp, C. F. E.; Vetter, S.; Yeluripati, J. B. First 20 years of DNDC (DeNitrification DeComposition): Model evolution. Ecol. Model. 2014, 292, 51-62.

36. Lehmann, J.; Kleber, M. The contentious nature of soil organic matter. Nature 2015, 528, $60-68$.

37. Foley, J. A.; DeFries, R.; Asner, G. P.; Barford, C.; Bonan, G.; Carpenter, S. R.; Chapin, F. S.; Coe, M. T.; Daily, G. C.; Gibbs, H. K.; Helkowski, J. H.; Holloway, T.; Howard, E. A.; Kucharik, C. J.; Monfreda, C.; Patz, J. A.; Prentice, I. C.; Ramankutty, N.; Snyder, P. K. Global consequences of land use. Science 2005, 309, 570-574.

38. Gougoulias, C.; Clark, J. M.; Shaw, L. J. The role of soil microbes in the global carbon cycle: Tracking the below-ground microbial processing of plant-derived carbon for manipulating carbon dynamics in agricultural systems. J. Sci. Food Agric. 2014, 94, 23622371. 
39. Encuesta sobre superficies y rendimientos cultivos; Ministerio de Agricultura y Pesca, Alimentación y Medio Ambiente: Madrid, 2017; http://www.mapama.gob.es/es/estadistica/temas/estadisticasagrarias/agricultura/esyrce/.

40. Council Directive on the landfill of waste. Council Directive 1999/31/EC, 1999;http://eur-lex.europa.eu/legalcontent/EN/TXT/PDF/?uri=CELEX:31999L0031\&from=EN.

41. Source separation of MSW. An overview of the source separation and separate collection of the digestible fraction of household waste, and of other similar wastes from municipalities, aimed to be used as feedstock for anaerobic digestion in biogas plants; IEA bioenergy: 2013; http://task37.ieabioenergy.com/files/datenredaktion/download/Technical\%20Brochures/source_separation_web.pdf.

42. Copado-Méndez, P. J.; Pozo, C.; Guillén-Gosálbez, G.; Jiménez, L. Enhancing the $\varepsilon-$ constraint method through the use of objective reduction and random sequences: Application to environmental problems. Comput. Chem. Eng. 2016, 87, 36-48.

43. Crenna, E.; Sozzo, S.; Sala, S. Natural biotic resources in LCA: Towards an impact assessment model for sustainable supply chain management. J. Clean. Prod. 2018, 172, 3669-3684.

44. Notarnicola, B.; Sala, S.; Anton, A.; McLaren, S. J.; Saouter, E.; Sonesson, U. The role of life cycle assessment in supporting sustainable agri-food systems: A review of the challenges. J. Clean. Prod. 2017, 140, 399-409.

45. Frischknecht, R. Life cycle inventory analysis for decision-making. Scope-dependent inventory system models and context-specific joint product allocation. Ph.D. dissertation, Swiss Federal Institute of Technology, Zurich, 1998. 

rainfall events: 1. model structure and sensitivity. J. Geophys. Res.1992, 97(D9), 97599776.

47. Frossard, E.; Skrabal, P.; Sinaj, S.; Bangerter, F.; Traore, O. Forms and exchangeability of inorganic phosphate in composted solid organic wastes. Nutr. Cycl. Agroecosyst. 2002, 62, 103-113.

48. Gagnon, B.; Demers, I.; Ziadi, N.; Chantigny, M. H.; Parent, L. -.; Forge, T. A.; Larney, F. J.; Buckley, K. E. Forms of phosphorus in composts and in compostamended soils following incubation. Can. J. Soil Sci. 2012, 92, 711-721.

49. García-Albacete, M.; Martín, A.; Cartagena, M. C. Fractionation of phosphorus biowastes: Characterisation and environmental risk. Waste Manage. 2012, 32, 10611068.

50. Hansen, T. L.; Bhander, G. S.; Christensen, T. H.; Bruun, S.; Jensen, L. S. Life cycle modelling of environmental impacts of application of processed organic municipal solid waste on agricultural land (Easewaste). Waste Manage. Res. 2006, 24, 153-166.

51. Tampio, E.; Marttinen, S.; Rintala, J. Liquid fertilizer products from anaerobic digestion of food waste: Mass, nutrient and energy balance of four digestate liquid treatment systems. J. Clean. Prod. 2016, 125, 22-32.

52. Zhang, X.; Davidson, E. A.; Mauzerall, D. L.; Searchinger, T. D.; Dumas, P.; Shen, Y. Managing nitrogen for sustainable development. Nature 2015, 528, 51-59.

53. Yoshida, H.; Nielsen, M. P.; Scheutz, C.; Jensen, L. S.; Bruun, S.; Christensen, T. H. LongTerm Emission Factors for Land Application of Treated Organic Municipal Waste. Environ. Model. Assess. 2016, 21, 111-124.

54. Brockmann, D.; Pradel, M.; Hélias, A. Agricultural use of organic residues in life cycle assessment: Current practices and proposal for the computation of field emissions and of the nitrogen mineral fertilizer equivalent. Resour. Conserv. Recycl. 2018, 133, 50-62. 
55. Esculier, F.; Le Noë, J.; Barles, S.; Billen, G.; Créno, B.; Garnier, J.; Lesavre, J.; Petit, L.; Tabuchi, J. P. The biogeochemical imprint of human metabolism in Paris Megacity: A regionalized analysis of a water-agro-food system. J. Hydrol. 2018, DOI:10.1016/j.jhydrol.2018.02.043.

56. Snyder, C. S.; Bruulsema, T. W.; Jensen, T. L.; Fixen, P. E. Review of greenhouse gas emissions from crop production systems and fertilizer management effects. Agric. Ecosyst. Environ. 2009, 133, 247-266.

57. Real Decreto por el que se regula la actividad de producción de energía eléctrica a partir de fuentes de energía renovables, cogeneración y residuos. Real Decreto 413/2014, 2014; https://www.boe.es/diario_boe/txt.php?id=BOE-A-2014-6123.

58. De Jonge, V. N.; Elliott, M.; Orive, E. Causes, historical development, effects and future challenges of a common environmental problem: Eutrophication. Hydrobiologia 2002, 475-476, 1-19. 